\title{
Dimensionamento amostral para avaliação da massa e diâmetro de frutos de nogueira-pecã
}

\author{
Sample size for evaluating the weight and diameter of pecan fruits
}

\author{
Alberto Cargnelutti Filho ${ }^{I}$ Tales Poletto ${ }^{\text {II }}$ \\ Marlove Fátima Brião Muniz ${ }^{\mathrm{III}}$ Carine Baggiotto ${ }^{\mathrm{IV}}$ Igor Poletto $^{\mathrm{V}}$
}

- NOTA -

\section{RESUMO}

O objetivo deste trabalho foi determinar o tamanho de amostra necessário para a estimação da média das massas do fruto, da casca e da amêndoa e dos diâmetros longitudinal e transversal de frutos de nogueira-pecã (Carya illinoinensis). Em 20 frutos, de cada uma de seis cultivares de nogueira-pecã ('Barton', 'Imperial', 'Importada', 'Mahan', 'Moneymaker' e 'Melhorada'), foi determinada a massa do fruto (MF), a massa da casca (MC) e a massa da amêndoa (MA) e mensurado o diâmetro longitudinal $(D L)$ e o diâmetro transversal (DT). Com os dados desses 20 frutos, para cada caractere e cultivar, foram calculadas medidas de tendência central e de variabilidade, verificada a normalidade e calculado o tamanho de amostra. Para cada caractere, foi verificada a homogeneidade de variâncias entre as cultivares e comparadas as médias de cultivares. Cinquenta frutos são suficientes para a estimação da média de $M F, M C, M A, D L$ e DT de frutos de nogueira-pecã, para erro de estimação de até $5 \%$ da média estimada, com grau de confiança de $95 \%$.

Palavras-chave: Carya illinoinensis, planejamento experimental, amostragem.

\section{ABSTRACT}

The objective of this research was to determine the sample size necessary to estimate the average mass of fruit, peel and almond and longitudinal and transverse diameters of fruits of pecan (Carya illinoinensis). On 20 fruits of each of the six cultivars of pecan ('Barton', 'Imperial', 'Importada', 'Mahan', 'Moneymaker'e 'Melhorada'), the fruit mass (MF), the shell mass (MC) and almond mass (MA) was determined and measured the longitudinal diameter $(D L)$ and transverse diameter (DT). With the data from these 20 fruits for each character and cultivar, measures of central tendency and variability were calculated, normality was checked and sample size was calculated. For each character, the homogeneity of variances among cultivars was verified and averages of cultivars were compared. Fifty fruits were enough to predict the average of $M F, M C, M A, D L$ and $D T$ fruit of pecan, with an estimation error equal to $5 \%$ of estimated average, with a degree confidence of $95 \%$.

Key words: Carya illinoinensis, experimental planning, sampling.

Cultivares de nogueira-pecã [Carya illinoinensis (Wangenh) K. Koch] diferenciam-se por suas características morfológicas, principalmente, nos frutos. A variabilidade morfológica dos frutos é revelada pelas múltiplas formas, tamanhos e colorações. Na comercialização de nozes (frutos), há classificações de acordo com a massa da amêndoa (semente), o tamanho da noz e as características da casca, que são utilizadas para definição de preços de mercado. Além disso, a regulagem das máquinas, na indústria de processamento, é feita de acordo com as características dos frutos, uma vez que o objetivo é retirar a amêndoa inteira. Portanto, é importante dimensionar o número de frutos, para avaliar com precisão os caracteres de massa e de diâmetro de frutos de nogueira-pecã.

Estudos sobre dimensionamento amostral de caracteres de frutos de pêssego (TOEBE et al., 2011), de maçã (TOEBE et al., 2011; 2014) e de abacaxizeiro (KRAUSE et al., 2013) têm sido

\footnotetext{
IDepartamento de Fitotecnia, Centro de Ciências Rurais (CCR), Universidade Federal de Santa Maria (UFSM), 97105-900, Santa Maria, RS, Brasil. E-mail: alberto.cargnelutti.filho@gmail.com. Autor para correspondência.

${ }^{\text {II } C u r s o ~ d e ~ E n g e n h a r i a ~ F l o r e s t a l, ~ U F S M, ~ S a n t a ~ M a r i a, ~ R S, ~ B r a s i l . ~}$

IIIDepartamento de Defesa Fitossanitária, CCR, UFSM, Santa Maria, RS, Brasil.

${ }^{\text {IV }}$ Curso de Engenharia Sanitária e Ambiental, UFSM, Santa Maria, RS, Brasil.

VUniversidade Federal do Pampa (UNIPAMPA), São Gabriel, RS, Brasil.
} 
realizados. No entanto, não foram encontrados, na literatura, estudos sobre o dimensionamento amostral para a avaliação de frutos de nogueira-pecã. Assim, o objetivo deste trabalho foi determinar o tamanho de amostra necessário para a estimação da média das massas do fruto, da casca e da amêndoa e dos diâmetros longitudinal e transversal de frutos de nogueira-pecã.

Em plantios de nogueira-pecã, localizados no município de Anta Gorda, Estado do Rio Grande do Sul (RS), no mês de maio de 2012, em 25 árvores matrizes de cada cultivar ('Barton', 'Imperial', 'Importada', 'Mahan', 'Moneymaker'e 'Melhorada'), foi coletado $1 \mathrm{~kg}$ de frutos de cada árvore matriz, totalizando $25 \mathrm{~kg}$ de frutos por cultivar. Os frutos foram embalados em sacos de papel, identificados e levados ao Laboratório de Fitopatologia do Departamento de Defesa Fitossanitária da Universidade Federal de Santa Maria, Santa Maria, RS. Após, foram colocados em bandejas plásticas, separados por cultivar e mantidos em temperatura ambiente. Dois meses após, em 20 frutos de cada cultivar, escolhidos aleatoriamente, foi determinada a massa do fruto (MF), em g, a massa da casca (MC), em g, e a massa da amêndoa (MA), em g, com balança digital de precisão de $0,01 \mathrm{~g}$. Após, foi mensurado o diâmetro longitudinal (DL), em mm, e o diâmetro transversal (DT), em mm, com paquímetro digital de precisão de $0,01 \mathrm{~mm}$. Diante do desconhecimento do tamanho de amostra necessário, para a estimação da média desses caracteres, consideraram-se 20 frutos como suficientes para o estudo do dimensionamento amostral. Para cada caractere (MF, MC, MA, DL e DT), mensurado nos 20 frutos $(n=20)$ de cada cultivar, foram calculados os valores mínimo e máximo, a média, a mediana, a variância, o desvio-padrão (s), o erro-padrão da média $(\mathrm{s} / \sqrt{\mathrm{n}})$ e o coeficiente de variação. Foi verificada a normalidade dos dados, em cada um dos 30 casos ( 6 cultivares $\times 5$ caracteres), por meio do teste de Kolmogorov-Smirnov (SIEGEL \& CASTELLAN JÚNIOR, 2006). Os dados dos 20 frutos foram utilizados de forma isolada no teste de Kolmogorov-Smirnov. A seguir, aplicou-se o teste F (bilateral), a 5\% de probabilidade, para testar a hipótese de homogeneidade das variâncias entre as cultivares (6 variâncias) em cada caractere ( 5 testes). $\mathrm{O}$ valor do teste $\mathrm{F}$ (bilateral) foi calculado pela razão entre as cultivares com maior e menor variância ( $\mathrm{F}=$ maior variância/menor variância) (BUSSAB \& MORETTIN, 2011), com 19 graus de liberdade no numerador e 19 graus de liberdade no denominador. Para a estimativa da variância de cada cultivar, o número de graus de liberdade foi obtido por $n-1$, em que n é o número de frutos de cada cultivar. Depois, para cada caractere, realizou-se a análise de variância e compararam-se as médias entre as cultivares, pelo teste Tukey, a 5\% de probabilidade de erro.

Para cada caractere (MF, MC, MA, DL e DT), de cada cultivar, foi calculado o tamanho de amostra (número de frutos, n) para as semiamplitudes (erros de estimação) do intervalo de confiança da média, fixadas em $1 \%, 2 \%, 3 \%, 4 \%, 5 \%, 6 \%, 7 \%$, $8 \%, 9 \%, 10 \%, 11 \%, 12 \%, 13 \%, 14 \%$ e $15 \%$ da média (m) do caractere, ou seja, $0,01 \times \mathrm{m}$ (maior precisão) e, em outro extremo, $0,15 \times \mathrm{m}$ (menor precisão), com grau de confiança (1- $\alpha$ ) de 95\%. Para isso, isolando $\mathrm{n}$ da expressão (erro de estimação $\left.=\mathrm{t}_{\alpha / 2} \mathrm{~s} / \sqrt{\mathrm{n}}\right)$, em que $(\mathrm{s} / \sqrt{\mathrm{n}})$ é erro-padrão da média, utilizada para a estimativa do intervalo de confiança da média, tem-se $n=\left[\left(t_{\alpha / 2} \mathrm{~s}\right) /(\text { erro de estimação) }]^{2} \quad\right.$ (BUSSAB \& MORETTIN, 2011), na qual $t_{\alpha / 2}$ é o valor crítico da distribuição $\mathrm{t}$ de Student, tal que $\mathrm{P}\left(\mathrm{t}>\mathrm{t}_{\alpha / 2}\right)=\alpha / 2$, com $\alpha=5 \%$ de probabilidade e (n-1) graus de liberdade, e s é a estimativa do desvio-padrão. O valor crítico da distribuição t de Student (t tabelado) foi obtido pela função INVT(probabilidade;graus_liberdade) do Microsoft Office Excel $^{\circledR}$ e, neste estudo, para o primeiro valor de $\mathrm{n} \quad(\mathrm{n}=20)$ correspondeu a $\operatorname{INVT}(0,05 ; 19)$, ou seja, 2,09302404985486. O tamanho de amostra foi calculado iterativamente até a sua convergência. As análises estatísticas foram realizadas com os aplicativos GENES (CRUZ, 2013) e Microsoft Office Excel ${ }^{\circledR}$.

Quanto aos caracteres massa do fruto (MF), massa da casca (MC), massa da amêndoa (MA), diâmetro longitudinal (DL) e diâmetro transversal (DT), houve diferenças entre as médias das cultivares, o que indica variabilidade genética desses caracteres de frutos de nogueira-pecã (Tabela 1). De maneira geral, os frutos das cultivares 'Barton', 'Imperial' e 'Melhorada' apresentaram maiores médias de MF, MC, MA e DT, comparadas às cultivares 'Importada', 'Mahan' e 'Moneymaker', porém estudo mais detalhado das diferenças entre as cultivares, quanto a esses caracteres de frutos, não foi o foco deste trabalho.

Em relação aos caracteres $\mathrm{MF}, \mathrm{MC}, \mathrm{MA}$, DL e DT, os valores mínimos e máximos e as medidas de dispersão (variância, desvio-padrão, erro-padrão da média e coeficiente de variação) em cada cultivar (Tabela 1) refletem a variabilidade existente entre os frutos. O teste $\mathrm{F}$ (bilateral), aplicado para testar a hipótese de homogeneidade de variâncias entre as cultivares (6 variâncias), revelou que as variâncias foram heterogêneas para os caracteres $\mathrm{MF}(\mathrm{F}=2,64$, valor- $\mathrm{p}=0,0406), \mathrm{MC} \quad(\mathrm{F}=5,16, \quad$ valor- $\mathrm{p}=0,0008)$, MA $\quad(F=3,60, \quad$ valor- $p=0,0075), \quad D L \quad(F=3,72$, 
Tabela 1 - Valores mínimo e máximo, média, mediana, variância, desvio-padrão, erro-padrão da média, coeficiente de variação (CV\%) e valor-p do teste de normalidade de Kolmogorov-Smirnov para cinco caracteres de nogueira-pecã (Carya illinoinensis), avaliados em 20 frutos de cada cultivar.

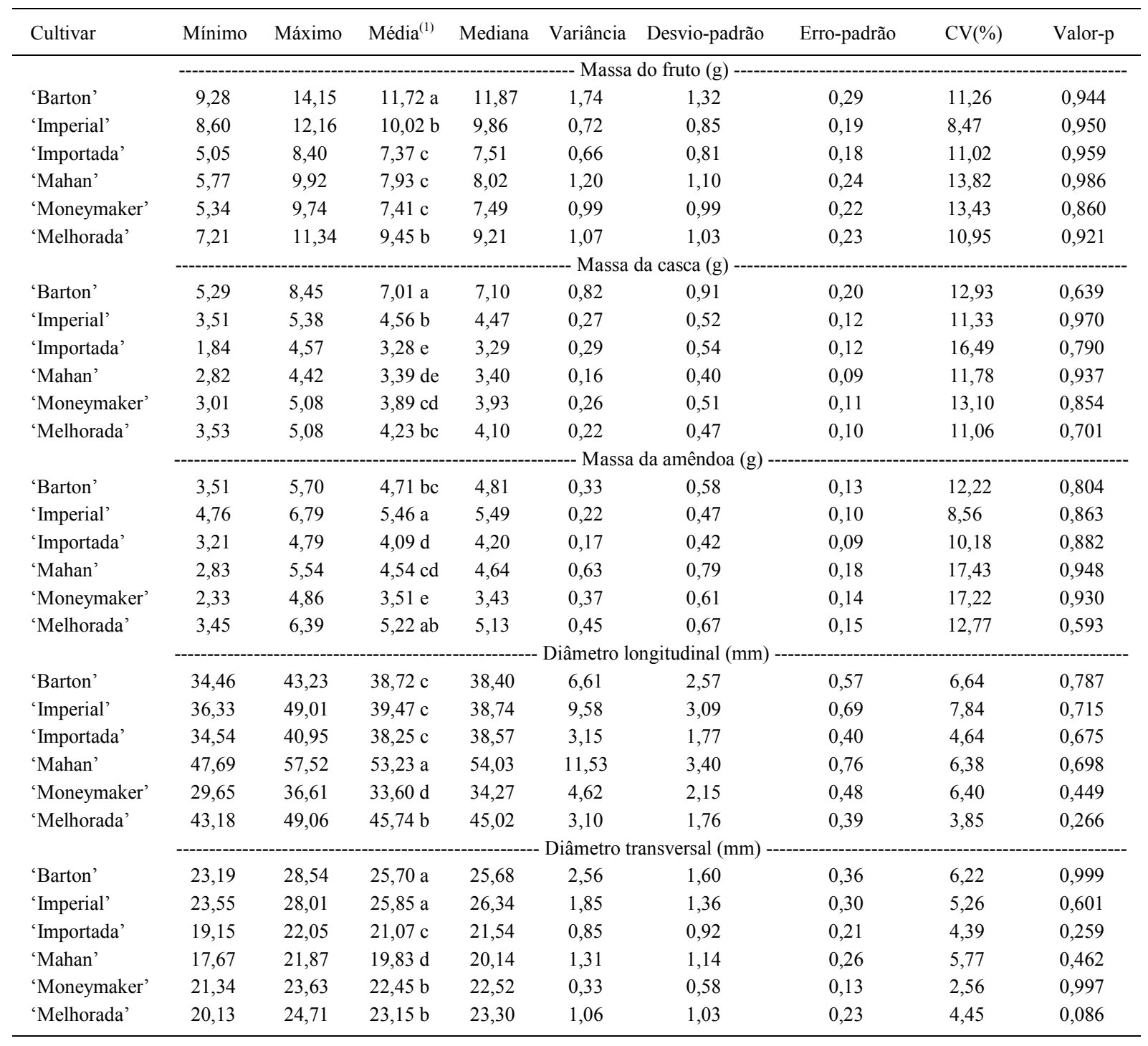

${ }^{(1)}$ As médias dos caracteres, não seguidas pela mesma letra na coluna, diferem pelo teste Tukey, a $5 \%$ de probabilidade de erro.

valor-p=0,0062) e DT $(\mathrm{F}=7,73$, valor- $\mathrm{p}=0,0000)$, o que indica que o tamanho de amostra difere entre as cultivares. Assim, conclui-se que o tamanho de amostra para avaliar MF, MC, MA, DL e DT de frutos de nogueira-pecã é dependente da cultivar e será maior para as cultivares com maior variabilidade e vice-versa. Variabilidade do tamanho de amostra entre formas de armazenamento dos frutos de pêssego e de maçã (tratamentos) (TOEBE et al., 2011) e entre cultivares de maçã (TOEBE et al., 2014) também foi constatada. O coeficiente de variação $(\mathrm{CV})$ médio de cultivares foi de $11,49 \%, 12,78 \%, 13,06 \%, 5,96 \%$ e de 4,78\%, respectivamente, para MF, MC, MA, DL e DT, o que sugere que o tamanho de amostra para a estimação da média, com mesma precisão, é maior para os caracteres relacionados à massa de frutos $(\mathrm{MF}$, MC e MA) e menor para aos caracteres relacionados ao diâmetro de frutos (DL e DT). Em frutos de abacaxizeiro (KRAUSE et al., 2013) e de maçã (TOEBE et al., 2014), também foi constatado maior tamanho de amostra para a massa e menor para aos caracteres relacionados ao diâmetro. A magnitude semelhante da média em relação à mediana e os elevados valores-p (valor-p $\geq 0,086$ ) do teste de Kolmogorov-Smirnov 
(Tabela 1$)$, nos 30 casos ( 6 cultivares $\times 5$ caracteres), indicam boa aderência dos dados à distribuição normal. Assim, pode-se inferir que os dados são adequados para o estudo do dimensionamento amostral, com base na distribuição t de Student.

O tamanho de amostra, para a estimação da média de MF, MC, MA, DL e DT, com erro de estimação igual a $1 \%$ da estimativa da média $(\mathrm{m})$ (maior precisão), oscilou entre 28 frutos para DT da cultivar 'Moneymaker' e 1.169 para MA da cultivar 'Mahan'
(Tabela 2). Portanto, a estimação da média de MF, MC, MA, DL e DT, nessas seis cultivares, com essa precisão, é difícil de ser praticada, pelo elevado número de frutos a serem mensurados. De maneira geral, para a mesma precisão, maiores tamanhos de amostra são necessários para a estimação dos caracteres relacionados à massa de frutos (MF, MC e MA) e menor para aos caracteres relacionados ao diâmetro de frutos (DL e DT). Podese interpretar também que, para tamanho de amostra fixo, menor precisão na estimativa da média é obtida

Tabela 2 - Tamanho de amostra (número de frutos) para estimação da média dos caracteres massa do fruto, massa da casca, massa da amêndoa, diâmetro longitudinal e diâmetro transversal de frutos de nogueira-pecã (Carya illinoinensis), para as semiamplitudes do intervalo de confiança de $95 \%$ (erros de estimação) iguais a 1\%,2\%,3\%, 4\%, 5\%, 6\%,7\%, 8\%, 9\%, 10\%, 11\%, 12\%, 13\%, $14 \%$ e $15 \%$ da estimativa da média.

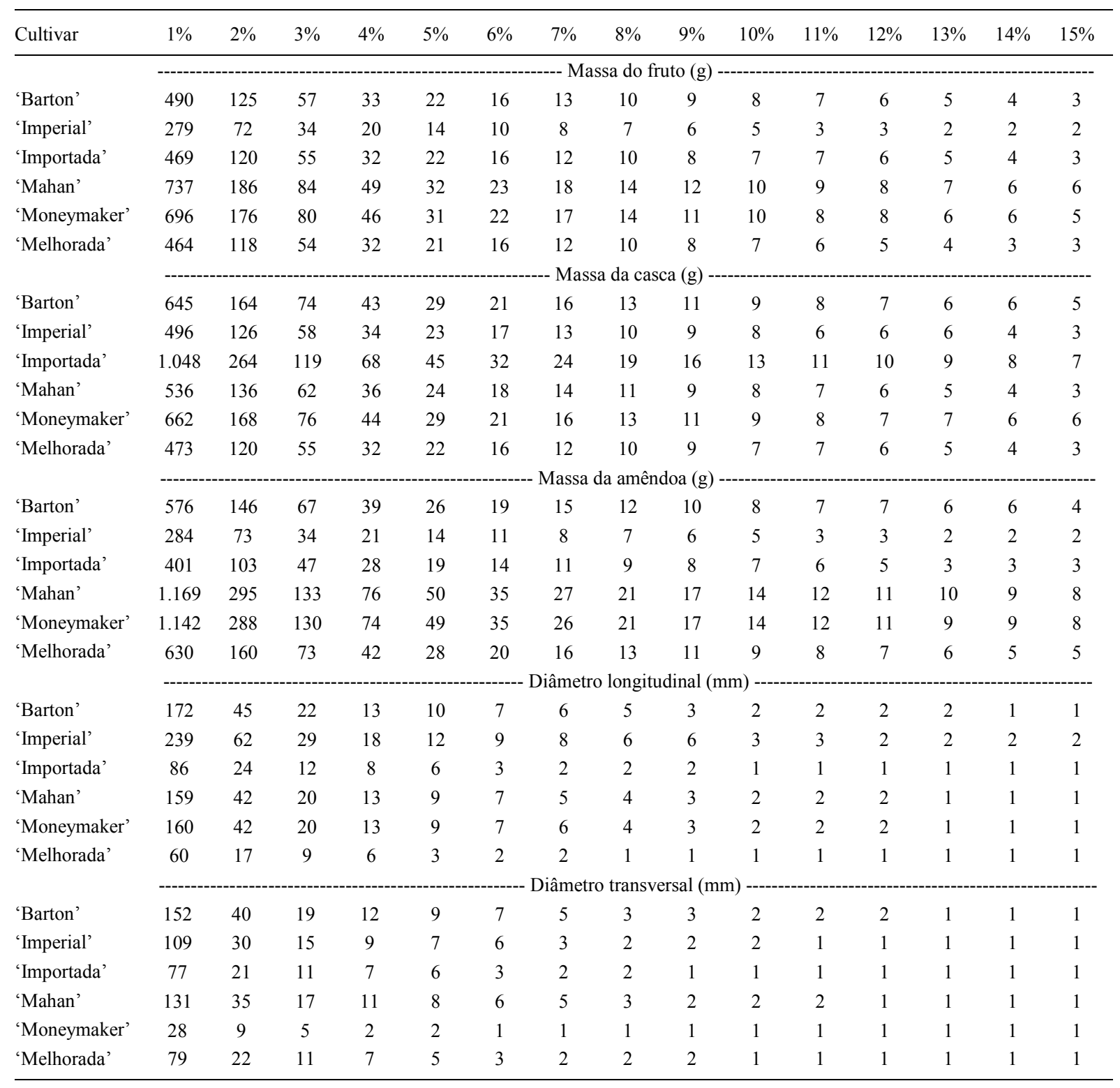


para caracteres relacionados à massa de frutos $(\mathrm{MF}$, MC e MA) e maior para os caracteres relacionados ao diâmetro de frutos (DL e DT). Tamanhos de amostra inferiores, porém com menor precisão ( $2 \%$ a $15 \%)$, podem ser utilizados no planejamento amostral para avaliação de massa e diâmetro de frutos (Tabela 2). Como exemplo, na prática, para essas seis cultivares, 50 frutos são suficientes para estimação da média de massa (MF, MC e MA) e diâmetro (DL e DT) de frutos de nogueira-pecã, para erro de estimação de até 5\% da média estimada, com grau de confiança de $95 \%$.

\section{AGRADECIMENTOS}

Ao Conselho Nacional de Desenvolvimento Científico e Tecnológico (CNPq), pela concessão de bolsa de Produtividade em Pesquisa para Alberto Cargnelutti Filho e Marlove Fátima Brião Muniz.

\section{REFERÊNCIAS}

BUSSAB, W.O.; MORETTIN, P.A. Estatística básica. 7.ed. São Paulo: Saraiva, 2011.540p.
CRUZ, C.D. GENES - a software package for analysis in experimental statistics and quantitative genetics. Acta Scientiarum Agronomy, v.35, p.271-276, 2013. Disponível em: $<$ http://periodicos.uem.br/ojs/index.php/ActaSciAgron/article/ view/21251/pdf $>$. Acesso em: 28 jun. 2014.

KRAUSE, W. et al. Tamanho ótimo de amostra para avaliação de caracteres de frutos de abacaxizeiro em experimentos com adubação usando parcelas grandes. Revista Brasileira de Fruticultura, v.35, p.183-190, 2013. Disponível em: $<$ http://www. scielo.br/pdf/rbf/v35n1/21.pdf $>$. Acesso em: 28 jun. 2014. doi: 10.1590/S0100-29452013000100021.

SIEGEL, S.; CASTELLAN JÚNIOR, N.J. Estatística nãoparamétrica para ciências do comportamento. 2.ed. Porto Alegre: Artmed, 2006. 448p.

TOEBE, M. et al. Dimensionamento amostral para avaliar firmeza de polpa e cor da epiderme em pêssego e maçã. Revista Ciência Agronômica, v.42, p.1026-1035, 2011. Disponível em: <http:// www.scielo.br/pdf/rca/v42n4/a27v42n4.pdf >. Acesso em: 28 jun. 2014. doi: 10.1590/S1806-66902011000400027.

TOEBE, M. et al. Tamanho de amostra para a estimação da média de caracteres de maçã. Ciência Rural, v.44, p.759-767, 2014. Disponível em: <http://www.scielo.br/pdf/cr/v44n5/ a12514cr2013-0203.pdf>. Acesso em: 28 jun. 2014. doi: 10.1590/ S0103-84782014000500001. 